\title{
Minimally invasive esophagectomy
}

\author{
Review of the literature
}

\author{
Heinz Wykypiel · Thomas Schmid · Philipp Gehwolf
}

Received: 1 November 2018 / Accepted: 14 February 2019 / Published online: 26 February 2019

(C) The Author(s) 2019

\begin{abstract}
Summary
Background Minimally invasive techniques have replaced the conventional open approach in many operations. For esophagectomy, it took quite a long time to become routine even in centers. The aim of this review was to demonstrate history and current status of minimally invasive esophagectomy and also robotic-assisted esophagectomy with its associated techniques.

Methods Selected literature on minimally invasive surgery for esophageal cancer was identified using a PubMed search for the period 1990-2018 with the search terms esophagectomy, minimal invasive, robotic, indocyanine fluorescein, enhanced recovery after surgery (ERAS), fast-track, nerve monitoring and its permutations.

Results Within the last two decades minimally invasive esophagectomy has found its way into clinical practice. It reduces perioperative morbidity with equivalent oncological outcome. It allows for better pulmonary results, less blood loss, less pain, and better quality of life. If robotic assisted esophagectomy helps to further improve the results is currently under investigation. Fast-track protocols have proven their value. Intraoperative nerve monitoring and indocyanine green fluorescein imaging of the perfusion of the gastric tube can lower perioperative complications.

Conclusions Minimally invasive surgery for esophageal malignancies offers advantages when performed in an environment with sufficient expertise and caseload. Whether robotic-assisted minimally invasive esophagectomy further improves the results
\end{abstract}

H. Wykypiel, MD ( $\bowtie) \cdot$ T. Schmid, MD · P. Gehwolf, MD Clinical Department of Visceral-, Transplantation and Thoracic Surgery, Medical University of Innsbruck, Anichstraße 35, 6020 Innsbruck, Austria heinz.wykypiel@i-med.ac.at has to be investigated in the future. Intraoperative nerve monitoring and visualization of the graft perfusion with indocyanine green fluorescein should be used where available. Enhanced recovery protocols after surgery have become standard.

Keywords Esophagectomy - Esophageal neoplasms · Robotics · Robotic surgical procedures · Minimally invasive surgical procedure

\section{Introduction}

During the 1990s, minimally invasive approaches rapidly became standard in Europe for many indications in abdominal surgery like cholecystectomy, appendectomy and hernia repair. In these technically easier procedures, the advantages of the open approach were so obvious and the learning curve was steep so that no surgical unit could spare it. Patients even asked for it. Moreover, since the competence in minimally invasive techniques grew rapidly in the surgical community, more demanding procedures followed and also found their place in daily routine. Sigma resections, laparoscopic colon resections, fundoplications, Heller myotomies and left pancreatic resections also became standard when specialized teams formed.

Of note, in about the same time period the treatment of most diseases became more complex so that the subspecialization within what we call "general surgery" went on. Subdivisions of upper gastrointestinal (GI) surgery (covering esophagus and bariatric/ metabolic surgery), coloproctology, hepatobiliopancreatic surgery, transplant surgery, thoracic surgery, hernia and abdominal wall surgery, endocrine surgery and also breast surgery formed, mostly in close cooperation with the theme-associated disciplines like oncologists, gastroenterologists and so on. 
Very early, pioneers of laparoscopic surgery were aiming to push the limits of what can be done minimally invasively. However, in these laparoscopic and video-assisted thoracoscopic (VATS) high-end procedures, it took longer to become widespread all over the world. Therefore, redo-surgeries, bariatric, colorectal, lung, pancreas and esophagus surgery were only added later to the list of what we call routine nowadays. Even some of them have not become routine yet. This has two reasons: on the one hand, they have a flatter (slower) learning curve and therefore demand a specialized dedication and on the other hand, the advantages of the minimally invasive approach is not so obvious that surgeons feel the strong need to do it. To the author's opinion, minimally invasive esophagus resections are a good example for that.

In 1992 Cushieri reported on endoscopic esophagectomy through a right thoracoscopic approach for the first time, followed by a series of several groups [1]. Nowadays, many specialized centers have implemented this technique. Nevertheless, the routine use of minimally invasive esophageal surgery is still under debate and is therefore not yet adopted in a widespread manner.

The aim of this review was to demonstrate history and current status of minimally invasive esophagectomy and also robotic-assisted esophagectomy with its associated techniques that are currently utilized in order to enhance safety.

\section{Patients and methods}

Review of selected literature on minimally invasive surgery for esophageal cancer. A PubMed search was performed for the period 1990-2018 with the search terms esophagectomy, minimal invasive, robotic, indocyanine green fluorescein, ERAS, fast track, nerve monitoring and its permutations. The selection of the papers was performed on discretion of the author, mainly driven by exclusivity, number of patients, and the level of evidence. Nevertheless, almost all "significant" publications on the topic are mentioned and cited.

\section{Results}

\section{History of minimally invasive esophagectomy}

As noted above, Cushiery already reported on five cases of endoscopic esophagectomy through a right thoracoscopic approach, followed by a paper on 26 procedures in 1994 [1, 2]. Consequently, surgeons all over the world worked with empathy and dedication to develop minimally invasive techniques of the existing different variations of esophageal resections [3-11]. Namely transhiatal, transthoracic and three-field (abdominal-thoracic--cervical) approaches found their position and therefore a more common use for a minimally invasive approach [10,
12-19]. In Austria, some specialized departments used their highly developed minimally invasive skills to perform minimally invasive esophageal resections with good outcomes even without publishing their experiences, e.g., Schmid T, Innsbruck and Szinicz G., Bregenz, Austria (personal communication). Others reported on small series more focused on feasibility [20-25], operative technique [26-28] and perioperative outcome $[11,29]$ than on oncological long-term data, quality of life or even cost analysis.

Thereafter in the 1990s and early 2000s, high-volume expert centers formed and as soon as the first large series were published [3], others felt justified to "try this at home". Nowadays, there are several well-known expert centers on minimally invasive esophagectomy (MIE) all over the world, developing better evidence on the various applied techniques, indications and outcomes. However, only $15 \%$ of esophagectomies worldwide are performed by using the conventional laparoscopic-thoracoscopic or robotic approach [30], although better global quality of life, physical function, fatigue, and pain 3 months after surgery have been demonstrated [31].

The newest kids on the block were implementation of telemanipulators called "operation robots" and the integration of enhanced vision such as HD-cameras and 3D imaging [32]. ICG-visualization of organ perfusion and the application of electric nerve stimulation, both with the aim to improve the patients' outcome, are also on their way to find their place in daily routine. All of them will be discussed below.

\section{Procedure choice: transthoracic, transhiatal and cervical access}

Presently there is no gold standard technique for esophagectomy. The choice of the technique strongly depends on tumor location and surgeons' preference and experience with one or the other technique. The most commonly applied minimally invasive approaches are combined abdominal and transthoracic approaches using the tube-shaped stomach pull-up as a substitute for the resected esophagus (Fig. 1). Two techniques, with the anastomosis intrathoracically (Ivor-Lewis) (Fig. 2 and 3) or in the left neck (McKeown) are the most used [33, 34]. Both of them provide an en bloc resection of the esophagus together with radical mediastinal lymph node dissection under direct visualization [35]. However, open transhiatal esophagectomy (THE; i.e. abdominal approach to the mediastinum, through the diaphragm) is still under debate as an alternative with lower morbidity in some, but not in all studies [36-38]. With avoiding single lung ventilation, it was considered a technique for rather unfit patients. Nevertheless, the extent of lymph node dissection in the upper mediastinum is very limited from the abdomen keeping in mind that even in adenocarcinoma of the distal esophagus, the rate of positive lymph nodes in the 


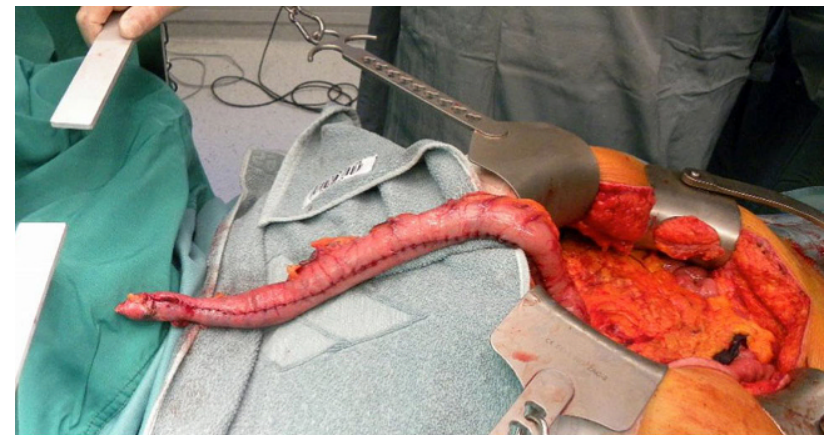

Fig. 1 The gastric tube as a conduit

upper mediastinum was as high as $10 \%$ in some studies! Therefore, transhiatal resections might show worse oncologic outcomes. However, laparoscopic or robotic assisted transhiatal esophagectomy has been shown to be an even lesser invasive alternative. Laparoscopic THE was demonstrated to be safe and feasible with evidence of reduced blood loss and shorter hospital stay. However, level 1 evidence is lacking and also evaluation of long-term oncologic outcomes is warranted [39,40].

\section{Hybrid esophagectomy}

Since minimally invasive techniques of esophagectomy are demanding, the implementation of such a program strictly depends on the previous experience of the team in high-end laparoscopic surgery as well as in minimally invasive thoracic surgery. The latter has found its way into daily routine relatively later than laparoscopy and the number of experts available to apply new techniques is scarce. Therefore, many teams around the world have adopted a so-called hybrid approach, using minimally invasive surgery in the field of their better expertise and combining it with a conventional access in the other compartment [41]. Some combine laparoscopy with thoracotomy while others prefer the thoracoscopic approach and perform the abdominal part of the operation by conventional midline laparotomy. Those preferring laparotomy argue that the mobilization of the gastric tube including a "Kocher's maneuver" can be done more easily in an open way and that the main advantage of MIE lies in a less invasive thoracic part. On the other hand, those performing laparoscopy and thoracotomy rely on a "safer" performance of the intrathoracic anastomosis e.g. with oversewing the circular stapled anastomosis in order to avoid leaks. In the MIRO trial [42, 43], 200 patients were randomized to either HMIE (hybrid minimally invasive esophagectomy, with thoracotomy) or open Ivor-Lewis esophagectomy. As a result, HMIE demonstrated to have less postoperative major morbidity, specifically significantly less pulmonary complications. Moreover, in a recent 3-year followup an overall survival of $67 \%$ (95\% confidence inter-

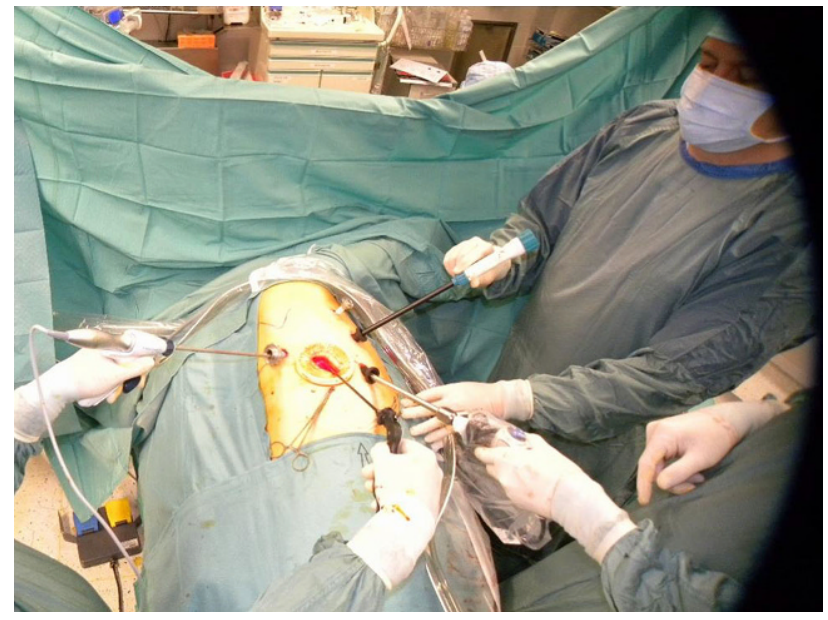

Fig. 2 Minimally invasive esophagectomy: trocar positioning thoracic part (lateral decubitus position)

val [CI] 57-75) in the HMIE group versus 55\% $(95 \%$ CI 45-64) in the open-procedure group was demonstrated [44]. In the MIOMIE trial, an Austrian group compared open esophagectomy versus HMIE (with thoracotomy) as well. They could show that morbidity, mortality, and oncological long-term outcome were equal to the classical open Ivor Lewis approach $[45,46]$.

However, with enough expertise, both parts can be accomplished minimally invasively when a stepwise approach with proctoring from a high-volume reference center is available in order to steepen the learning curve. Complete MIE has shown to be better than HMIE in terms of postoperative pain and pulmonary complications [47].

Fellowships at high-volume centers, proctoring by experts and credentialing seems reasonable [48].

Like in other highly demanding surgeries like pancreatic resections, the technical term "learning curve" means morbidity, mortality, pain, fear and even high financial burden in daily practice. Osugy et al. have defined the number of 17 MIEs to establish basic skills and a number of 34 cases to attain a similar or better outcome than by conventional (open) approach [49]. In a consensus paper Visser et al. has determined consensus among European MIE experts and identified fundamental items required for training MIE [50].

\section{Completely minimally invasive esophagectomy}

\section{Reviews and meta-analyses}

To date, several reviews comparing conventional (open) with minimally invasive techniques are available.

In 2009, 10 case-controlled studies and one systematic review were analyzed [51]. To sum up, in MIE, less blood loss (577 vs. $312 \mathrm{ml}$ ), a reduction of overall complications (60.4 vs. $43.8 \%$ ), a reduction of intensive care unit (ICU) stay (7.6 vs. 4.5 days) and a reduction of overall hospital stay (19.6 vs. 14.9 


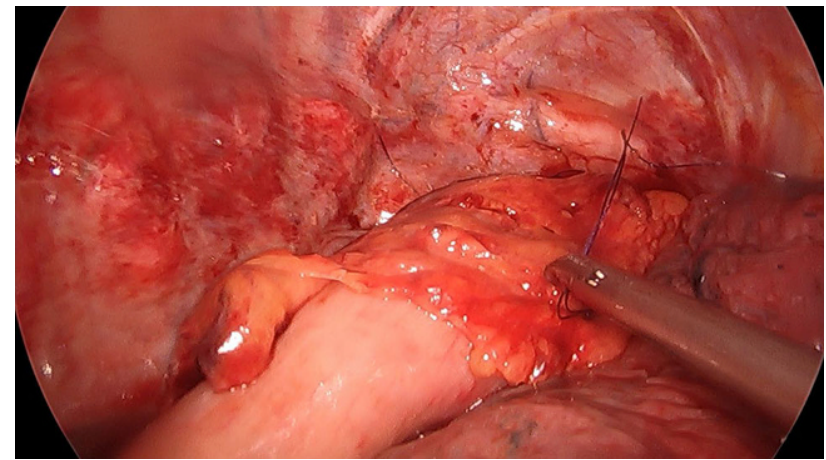

Fig. 3 Minimally invasive esophagectomy (Ivor-Lewis): intrathoracic view on the anastomosis in the right upper mediastinum (circular stapled end-to-side esophagogastrostomy, covered with an omental flap)

days) was demonstrated. In detail, pulmonary complications occurred in 22.9 vs. $15.1 \%$, the number of mean lymph node harvest was 23.8 vs. 20.2, indicating a benefit for those patients who underwent minimally invasive esophagectomy (MIE).

A systematic review and meta-analysis of 12 studies (MIE vs. HMIE vs. OE) demonstrated no significant difference in 30-day mortality for MIE and HMIE compared to the $\mathrm{OE}$. The minimally invasive procedures had significantly lower blood loss, shorter ICU stay, total hospital stay and respiratory complications compared to OE [52].

A recent meta-analysis including 1549 patients showed a reduced blood loss and a better 2-year survival rate following MIE. Anastomosis leakage was similar compared to the open approach [53].

\section{Randomized controlled trials}

Luketich et al. from a dedicated high-volume center in Pittsburgh (UPMC) published a retrospective analysis of over 1000 patients who underwent MIE for cancer within 15 years. He draw the conclusion that MIE reduces perioperative complications entailing a quicker recovery, with a mortality rate of $1.6 \%$ [54].

Currently, several randomized and multicenter trials are available comparing MIE with conventional approaches.

In the prospective randomized TIME trial, Biere et al. [55] demonstrated a lower yield for pulmonary complications within the first two postoperative weeks in the MIE group (29 vs. 9\%). Moreover, 34 vs. $11.9 \%$ were shown to have pulmonary in-hospital infections. For in-hospital mortality, one patient in the open esophagectomy group died from anastomotic leakage and two in the minimally invasive group from aspiration and mediastinitis after anastomotic leakage. The authors concluded that these findings provide evidence for the short-term benefits of minimally invasive esophagectomy for patients with resectable esophageal cancer. A follow-up study

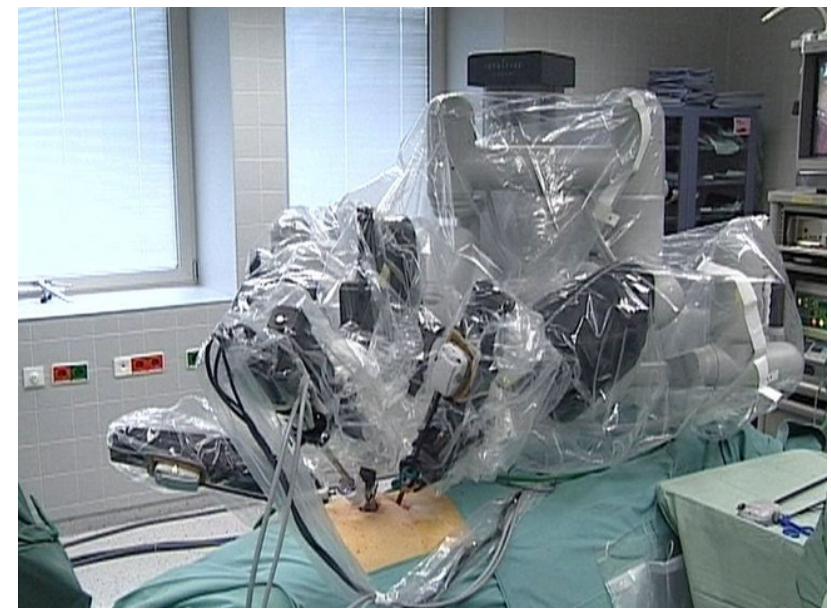

Fig. 4 The DaVinci operation robot (first generation, Intuitive Surgical, Intl.): patient

of their patients showed similar disease-free (36 vs. $40 \%$ ) and overall (40 vs. 51\%) 3-year survival [56]. Nguyen et al. demonstrated similarly the feasibility and safety of MIE over the conventional open approach in 46 cases [4].

Moreover, Smithers et al. demonstrated a similar 3-year survival rate in a study with 114 open, 309 thoracoscopic-assisted, and 23 total MIEs. The groups were comparable with respect to preoperative variables. The differences in the postoperative variables were less median blood loss in the thoracoscopic-assisted and total MIE groups versus open (400 vs. 300 vs. $600 \mathrm{ml}$ ). They found a longer time for total MIE versus thoracoscopic-assisted and open (330 vs. 285 vs. $300 \mathrm{~min}$ ), a longer median time in hospital for open versus thoracoscopic-assisted versus total MIE (14 vs. 13 vs. 11 days) and less stricture formation in the open versus thoracoscopic-assisted versus total MIE (6.1 vs. 21.6 vs. $36 \%$ ). There were no differences in lymph node retrieval for each of the approaches [4, 57].

In the ongoing randomized ROMIO trial, comparing MIE with hybrid with open esophagectomy, patients' abdomen and thorax will be dressed all over postoperatively in order to blind the treating personnel regarding the evaluation of postoperative pain [58, 59]. Two more randomized trials are still ongoing and the results will be shown at a future date [35, 60].

\section{Matched analysis}

In a propensity score-matched comparison $652 \mathrm{OE}$ versus 735 MIE (444 paired cases) with squamous cell carcinoma, Wang et al. found MIE to be superior in terms of operation time, blood loss, hospital stay, readmissions to ICU, major complications, quality of life, with a comparable number of retrieved lymph nodes and the same 2-year overall survival rate [61]. 


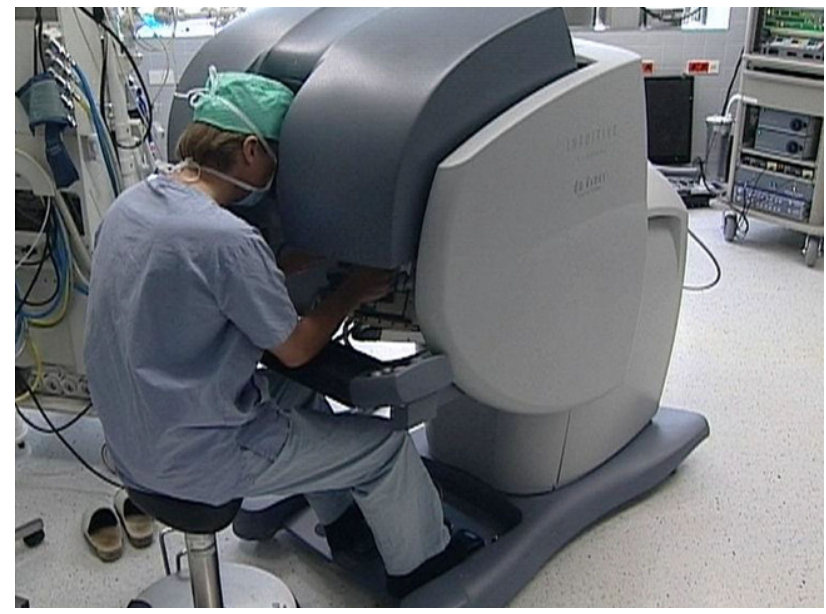

Fig. 5 The DaVinci operation robot (first generation): surgeon's console (Da Vinci first Generation, Intuitive Surgical, Intl.)

\section{Databases}

Using the data from the Society of Thoracic Surgeon Database, 3780 esophageal resections were analyzed. Compared with open esophagectomy, MIE was shown to have longer operation times and a higher rate of reoperation, whereas overall morbidity and mortality were similar. This was interpreted as an effect of the learning curve [62].

A population-based national study of all English National Health Service Trusts from April 2005 to March 2010 included 75,502 esophagectomy procedures in an analysis. In all, 1155 of them were accomplished minimally invasive. There was no difference in 30 -day mortality $(4.3 \%$ vs $4.0 \% ; P=0.605)$ and overall medical morbidity $(38.0 \%$ vs $39.2 \% ; P=0.457)$ rates between open and MIE groups, respectively. A higher reintervention rate was associated with the MIE group than with the open group $(21 \%$ vs $17.6 \%, P=0.006$; odds ratio, 1.17; 95\% confidence interval, 1.00-1.38; $P=0.040$ ). It can be assumed that between 2005 and 2010, most of the centers were somehow within their learning curve ... An actual update of the study would be interesting [63].

\section{Robotic}

In the early 2000s, the three-arm Da Vinci (Intuitive, Inc. Intl.) telemanipulator (so-called "operation robot") attracted the surgeons' interest and gained worldwide use [64]. In the Medical University Innsbruck, we performed all types of laparoscopic and thoracoscopic standard operations of that time by using it ([65-74]; Figs. 4, 5, 6 and 7). To sum up, socalled "standard" laparoscopic operations can easily be performed faster and cheaper with conventional laparoscopic technique by trained surgeons. The newer four-arm model of the DaVinci operation robot has several improvements with the potential of a better versatility and therefore lessens the degree to that an

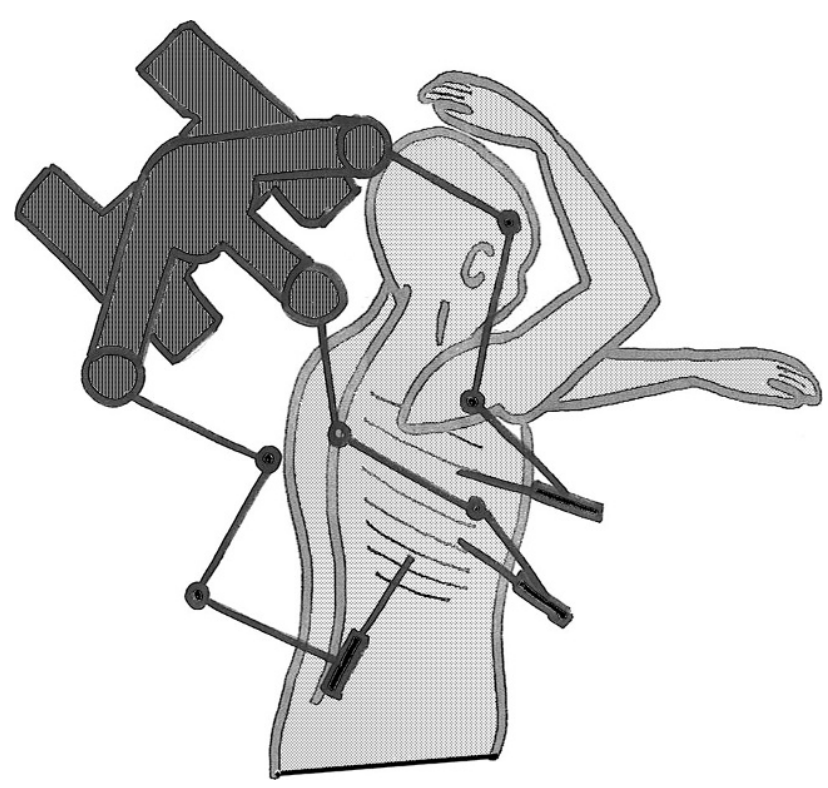

Fig. 6 Robotic-assisted minimally invasive esophagectomy: robot trocar positioning, thoracic part

on-table assistant has to contribute to the operation in between the former large moving robot arms.

When it comes to esophageal resections, surgeons hope to overcome the shortcomings of conventional thoracoscopy with non-articulated instruments due to the fulcrum effect of the thoracic wall, the remote position of the diaphragmatic hiatus and the meticulous lymph-node dissection in the upper mediastinum, sparing the recurrent laryngeal nerve and the vagus nerve. Better maneuverability, motion scaling, tremor filter and particularly a much more comfortable working position for the surgeon promise a smoother workflow with hopefully better outcomes (Fig. 8). However, it will be difficult to prove a better clinical outcome for the patient compared to conventional MIE [75].

\section{First series}

Several studies have been published since the first description of robotic assisted minimally invasive esophagectomy (RAMIE) by Horgan et al. in 2003 [76]. However, they are difficult to compare since a wide spectrum of different techniques is used. Robotic assisted transhiatal esophagectomy (RATE) [39, 76, 77], robotic assisted McKeon esophagectomy (RAMIME) [78] and robotic assisted Ivor-Lewis esophagectomy (RILE) including various hybrid applications make it hard to compare them systematically $[79,80]$.

\section{Reviews}

Kumar et al. published a review on 295 procedures: The robot seems not to be an advantage for the abdominal part with its wide operation field from the lower border of the duodenum until far up into the lower mediastinum, the therefore necessary bidirectional view and the intraoperative position change of 


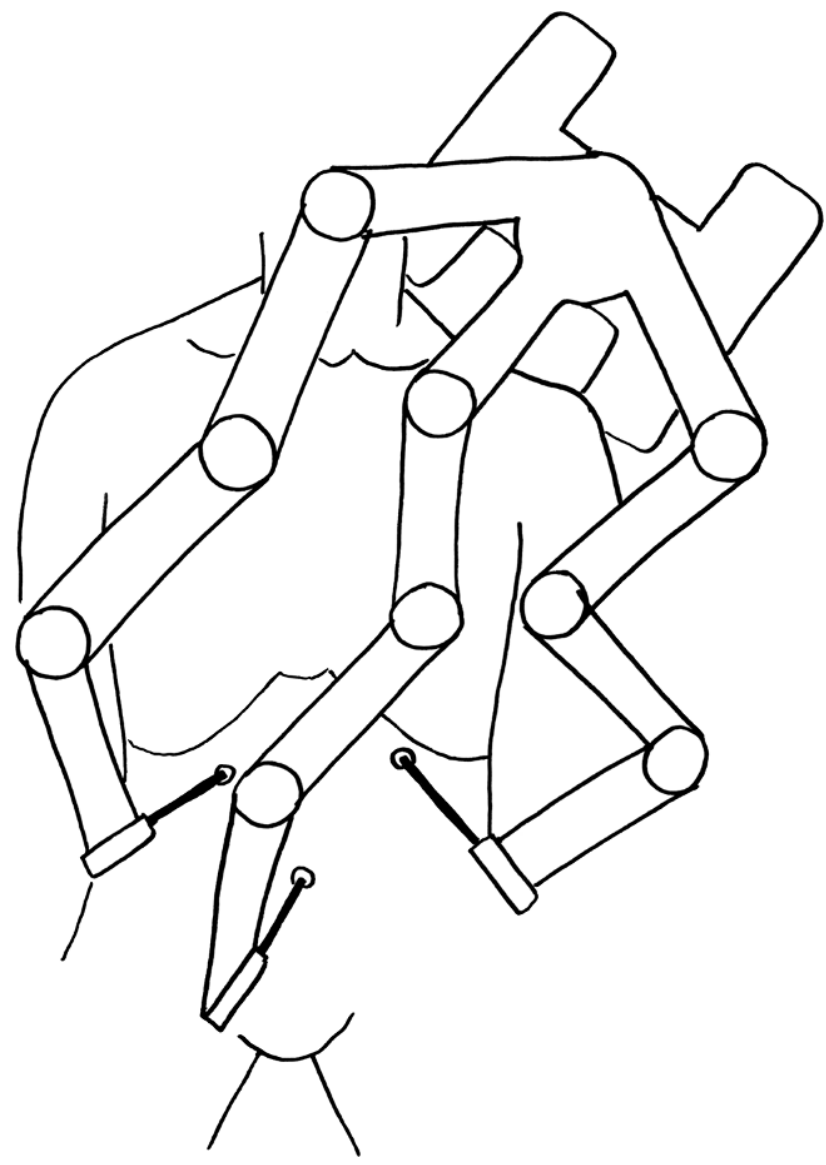

Fig. 7 Robotic-assisted minimally invasive esophagectomy: robot trocar positioning, abdominal part

90 degrees to the right for the creation of the feeding jejunostomy; therefore, the abdominal part is often performed by conventional laparoscopy. Nevertheless, for lymphadenectomy of the celiac axis, a transient use of the robot might be helpful. On the other hand, the remote areas in the mediastinum that have to be addressed for lymph node harvesting together with the need for precision to avoid damage of nerves and adjacent organs seem to be an ideal working field for the robot. Just as well, tumors in the upper mediastinum and remote paratracheal lymph node metastases are described as an ideal application field for the robot $[81,82]$.

The recently available studies on RAMIE are outlined shortly as follows:

\section{Case series}

In 2007, Kernstine et al. published the first series of RAMIME with a morbidity rate of $29 \%$ [78].

In 2012, Dunn et al. reported on 40 patients with RATE, having an anastomotic insufficiency rate of $25 \%$ and a stricture rate of $67 \%$. He clearly showed improvement by the time indicating the learning curve, but a transhiatal approach still seems questionable [83]. In the same year, Boone et al. published 47 RAMIME with an overall morbidity of $46.5 \%$. Retro-

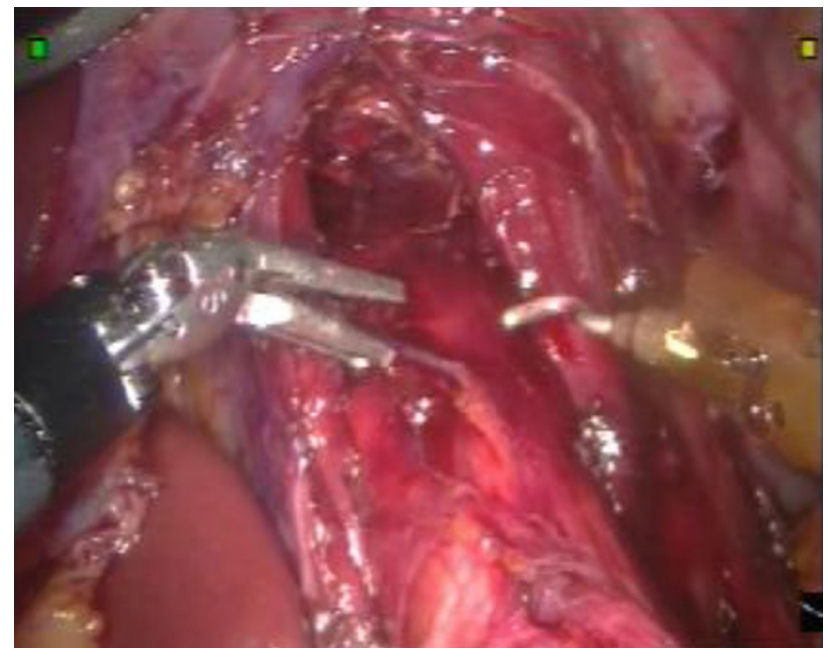

Fig. 8 Robotic tools enabling laparoscopic movements imitating the human hand ( $\mathrm{Da}$ Vinci first Generation, Intuitive Surgical, Intl.)

spectively, compared to these open esophagectomies, a significant reduction in pulmonary complications was noted (57\% vs. $33 \%$ ) [84, 85$]$.

Cerfolio et al. reported on 85 Ivor-Lewis esophagectomies between 2011 and 2015 with mixed technique, either laparoscopic or robotic abdominal and robotic assisted thoracoscopy. He calculated a major morbidity rate of $36.4 \%$, but a considerably high mortality rate of $10.6 \%$, mostly attributed to patient selection and anastomotic insufficiencies. Therefore, he changed the technique from hand sewn to stapled anastomosis. Moreover, patient selection was modified in terms of nutritional status, cardiopulmonary performance and risk factors related with liver disease [86, 87].

In 2014 Trugeda et al. [88] and in 2016 Bongiolatti et al. [89] reported on small initial series of RAMIE with hand sewn anastomoses with leak rates of 29 and $25 \%$, respectively, and both series had a mortality rate of zero. Although more feasible than with conventional MIE, intrathoracic robotic hand sewn anastomoses are demanding. Hence, Haverkamp et al. [90] found in a recent worldwide survey among specialists that $77 \%$ of the experts preferred a stapled anastomosis in the thorax and a $64 \%$ preferred a hand-sewn anastomosis in the neck. Interestingly, more than half of cervical anastomoses' insufficiencies leak into the chest, leading to more serious clinical consequences (ICU, length of stay, time to oral intake) than those that are confined to the neck [91].

\section{Comparative studies}

In 2012, Weksler et al. compared 11 RAMIE with 26 MIE patients. They failed to demonstrate a significant difference in postoperative morbidity, length of stay and number of retrieved lymph nodes [92].

Yerokun et al. also did not find any clear advantage for the robot over MIE: Perioperative outcomes and 3-year oncological results in T1-3N0-3M0 cancers 
of the distal and middle esophagus were comparable. However, MIE and RAMIE patients had shorter hospital stay and a higher number of retrieved lymph nodes compared to OE [93].

Van der Sluis et al. compared 108 RAMIE patients with a conversion rate of $19 \%$. A high number of R0 resections as well as a median number of 26 lymph nodes was shown. Of note, median follow-up was 58 months and 5-year survival was $42 \%$ [94].

In 2017 Okusanya et al. from the Pittsburgh group (UPMC) published the results of 26 RAMIE cases, including 2 RAMIME and 23 RILE. Anastomotic leakage rate, number of retrieved lymph nodes and conversion rate was similar to their previously reported conventional MIE [95].

Kim et al. [82] and Park et al. [96] recently reported on the application of the operation robot for lymph node dissection in the upper mediastinum with a number of 10 lymph nodes in mean from the upper mediastinum with a recurrent laryngeal nerve palsy rate of $26.3 \%$.

\section{Randomized controlled trials}

The latest publication is the so-called ROBOT trial, a single-center randomized controlled trial from an expert center in Utrecht, Netherlands. They assigned 112 patients comparing RAMIE versus open transthoracic esophagectomy (OE) and found that RAMIE resulted in a lower percentage of overall (59 vs. $80 \%$ ), surgery-related and cardiopulmonary complications with lower postoperative pain, better short-term quality of life, and a better short-term postoperative functional recovery compared to OE. Oncological outcomes at a medium follow-up of 40 months were comparable and in concordance with the highest standards nowadays [97].

\section{Database}

One recent review uses the National Cancer Data Base (NCDB). It was queried for patients diagnosed with pathologic Stage 0-III esophageal cancer from 2010-2015. Of 5553 patients that met criteria, 28.4\% underwent MIE, $7.8 \%$ RAMIE, and $63.8 \%$ open esophagectomy. From 2010-2015 an increasing trend was seen for both minimally invasive approaches, with MIE surpassing the number of open esophagectomies. Unplanned 30-day readmissions, 30-day and 90-day mortality rates were not significantly different between the different groups. LOS was significantly shorter in MIE and RAMIE, compared to OE (9 vs. 9 vs. 10 day). MIE and RAMIE had comparable survival rates compared to $\mathrm{OE}$ with no significant differences in median overall survival estimates after propensityscore matching (log-rank $p=0.603$ ); with a trend for increased survival in RAMIE. Both minimally invasive approaches had significantly higher median lymph node counts (15 vs. 17 . vs. 13) which may provide important differences in postoperative upstaging. The authors draw the conclusion that trends in MIE use is surpassing the open approach. Minimally invasive approaches are becoming the preferred approach with non-inferior long-term results compared to open esophagectomies. A significantly higher lymph node yield was seen for RAMIE and MIE [98].

\section{Lateral decubitus versus prone}

Patient positioning for MIE or RAMIE is also under debate: lateral decubitus versus prone position is debated against each other [99, 100]. Prone position of the patient allows for easier dissection of the esophagus since gravity keeps lung and blood down, thereby enlarging the operative field. Therefore, single lung ventilation is not necessary, thus reducing venous shunting. Moreover, it is more ergonomic for the surgeon. On the other hand, lateral decubitus positioning of the patient makes it easier to reach the upper mediastinum in order to perform lymphadenectomy along the vagus nerve. For those coming from open surgery, it offers a similar anatomic aspect and is also better suitable for emergency conversion to open surgery. To overcome the shortcomings of both methods, a semi-prone positioning with turning the table to the surgeon's needs seems to be a well-accepted compromise.

\section{Three-dimensional imaging}

For better visual depth perception, three-dimensional (3D) cameras seem promising and might even be a more viable technique over two-dimensions (2D) in terms of short-term outcomes for patients with esophageal cancer [32, 101, 102]. In the current operation robots, they are standard anyway.

\section{Visualization of the gastric tube's perfusion}

Healing of the anastomosis depends mainly on perfusion of the gastric tube. Therefore, identification of a well-perfused part of the stomach for positioning the anastomosis is desirable. Imaging of the tube's perfusion with indocyanine fluorescein angiography seems promising and might lower the rate of anastomotic insufficiencies. Additional technologies like image flattening, color segmented fluorescence, overlay mode and spy mode might help to standardize imaging of perfusion and even allow for working under fluorescence imaging. However, absolute quantification of blood flow is not possible and preliminary data are controversial (Fig. 9; [103-110]).

\section{Nerve monitoring}

Recurrent laryngeal nerve monitoring (RNM) in esophagectomy was performed for the first time in 2001 by Hemmerling et al. [111]. It took several years until its clinical usefulness had been proven either in the mediastinum or in the neck. It has no impact 
Fig. 9 Laser-induced fluorescence of indocyanine green tissue angiography for evaluation of the gastric conduit (Pinpoint Camera, Stryker Inc., USA)
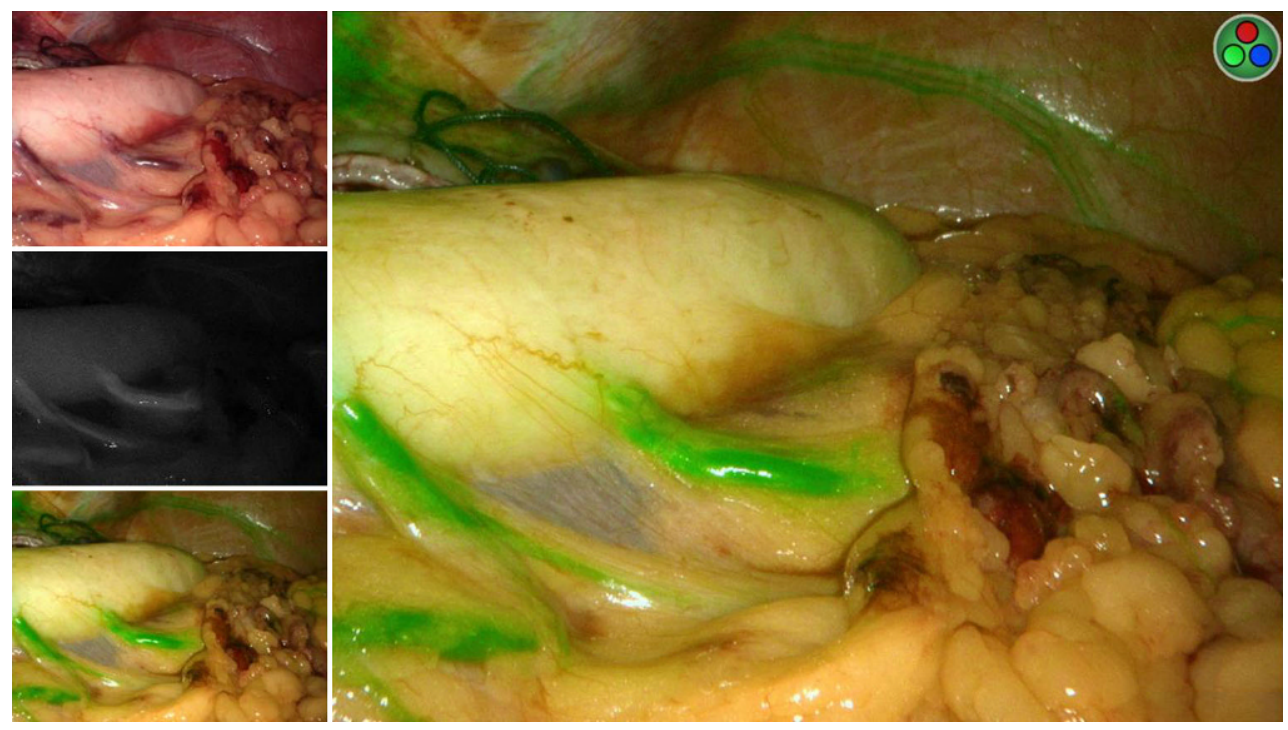

in operative time, but significantly reduces postoperative vocal cord palsy and consequently pulmonary complications [112-120].

\section{Enhanced recovery/fast track protocols}

Enhanced recovery after surgery (ERAS) protocols aim to preserve physiologic functions after surgery. Bed rest, opioids, long fasting, excessive intravenous fluid intake, tubes and drains etc. have been proven to be more harmful than beneficial in the majority of cases despite this was part of "surgical culture" since the ancient times of surgery. ERAS protocols have proven their value in almost all surgical subspecialties. Particularly patients after major surgeries including esophagectomy should profit from this newer fasttrack philosophy. In the recent years, ERAS protocols also found their way into clinical practice enabling an improvement of the results and even lowering overallcosts for esophagectomy [121-135].

\section{Conclusion}

Minimally invasive esophagectomy reduces perioperative complications with equivalent oncological outcome. It allows for better pulmonary results, less blood loss, less pain and a better quality of life when performed by well-trained surgeons with a sufficient caseload. Transthoracic approaches are superior to transhiatal techniques. Population-based studies show discordant results from expert centers. Therefore, proctoring and credentialing are crucial. Whether robotic assisted esophagectomy helps to further improve the results is currently under investigation. Fast-track protocols can be considered standard. Intraoperative nerve monitoring should be applied where available. The value of fluorescent angiography imaging to prevent anastomotic leaks needs further investigation.
Funding Heinz Wykypiel, Thomas Schmid and Philipp Gehwolf herewith declare that they have no financial disclosure.

Funding Open access funding provided by University of Innsbruck and Medical University of Innsbruck.

Conflict of interest H. Wykypiel, T. Schmid and P. Gehwolf declare that they have no competing interests.

Open Access This article is distributed under the terms of the Creative Commons Attribution 4.0 International License (http://creativecommons.org/licenses/by/4.0/), which permits unrestricted use, distribution, and reproduction in any medium, provided you give appropriate credit to the original author(s) and the source, provide a link to the Creative Commons license, and indicate if changes were made.

Publisher's Note Springer Nature remains neutral with regard to jurisdictional claims in published maps and institutional affiliations.

\section{References}

1. Cuschieri A, Shimi S, Banting S. Endoscopic oesophagectomy through a right thoracoscopic approach. J R Coll Surg Edinb. 1992;37(1):7-11.

2. Cuschieri A. Thoracoscopic subtotal oesophagectomy. Endosc Surg Allied Technol. 1994;2(1):21-5.

3. Luketich JD, Alvelo-Rivera M, Buenaventura PO, Christie NA, McCaughan JS, Litle VR, et al. Minimally invasive esophagectomy: outcomes in 222 patients. Ann Surg. 2003;238(4):486-94. discussion94-5.

4. Nguyen NT, Roberts P, Follette DM, Rivers R, Wolfe BM. Thoracoscopic and laparoscopic esophagectomy for benign and malignant disease: lessons learned from 46 consecutive procedures. J Am Coll Surg. 2003;197(6):902-13.

5. Dexter SP, Martin IG, McMahon MJ. Radical thoracoscopic esophagectomy for cancer. Surg Endosc. 1996;10(2):147-51.

6. Peracchia A, Rosati R, Fumagalli U, Bona S, Chella B. Thoracoscopic dissection of the esophagus for cancer. Int Surg. 1997;82(1):1-4. 
7. Luketich JD, Pennathur A. How to keep the treatment of esophageal disease in the surgeon's hands. Ann Thorac Surg. 2008;85(2):S760-S3.

8. DePaula AL, Hashiba K, Ferreira EA, de Paula RA, Grecco E. Laparoscopic transhiatal esophagectomy with esophagogastroplasty. Surg Laparosc Endosc. 1995;5(1):1-5.

9. Watson DI, Jamieson GG, Devitt PG. Endoscopic cervico-thoraco-abdominal esophagectomy. J Am Coll Surg. 2000;190(3):372-8.

10. Nguyen NT, Follette DM, Wolfe BM, Schneider PD, Roberts P, Goodnight JE Jr. Comparison of minimally invasive esophagectomy with transthoracic and transhiatal esophagectomy. Arch Surg. 2000;135(8):920-5.

11. Law S, Fok M, Chu KM, Wong J. Thoracoscopic esophagectomy for esophageal cancer. Surgery. 1997;122(1):8-14.

12. Collins G, Johnson E, Kroshus T, Ganz R, Batts K, Seng J, et al. Experience with minimally invasive esophagectomy. Surg Endosc. 2006;20(2):298-301.

13. Costi R, Himpens J, Bruyns J, Cadiere GB. Totally laparoscopic transhiatal esophago-gastrectomy without thoracic or cervical access. The least invasive surgery for adenocarcinoma of the cardia? Surg Endosc. 2004;18(4):629-32.

14. Leibman S, Smithers BM, Gotley DC, Martin I, Thomas J. Minimally invasive esophagectomy: short- and long-term outcomes. Surg Endosc. 2006;20(3):428-33.

15. Luketich JD, Schauer PR, Christie NA, Weigel TL, Raja S, Fernando HC, et al. Minimally invasive esophagectomy. Ann Thorac Surg. 2000;70(3):906-11. discussion 11-2.

16. Martin DJ, Bessell JR, Chew A, Watson DI. Thoracoscopic and laparoscopic esophagectomy: initial experience and outcomes. Surg Endosc. 2005;19(12):1597-601.

17. Nguyen NT, Follette DM, Lemoine PH, Roberts PF, Goodnight JE Jr. Minimally invasive Ivor Lewis esophagectomy. Ann Thorac Surg. 2001;72(2):593-6.

18. Nguyen NT, Schauer P, Luketich JD. Minimally invasive esophagectomy for Barrett's esophagus with high-grade dysplasia. Surgery. 2000;127(3):284-90.

19. Yamamoto S, Kawahara K, MaekawaT, ShiraishiT, Shirakusa T. Minimally invasive esophagectomy for stage I and II esophageal cancer. Ann Thorac Surg. 2005;80(6):2070-5.

20. Gossot D, Toledo L, Cortes A. Minimal access esophagectomy: where are we up to? Semin Laparosc Surg. 2000;7(1):2-8.

21. Sabanathan S, Mearns AJ, Richardson J. Endoscopic oesophagectomy through a right thoracoscopic approach. JR Coll Surg Edinb. 1992;37(4):284-5.

22. Gossot D, Fourquier P, Celerier M. Thoracoscopic esophagectomy: technique and initial results. Ann Thorac Surg. 1993;56(3):667-70.

23. Slattery P, Hinder R, Gengler J, Montag M, Thomas D, Filipi CJ, et al. Thoracoscopically assisted esophagectomy with gastric pull-up for esophageal cancer. Surg Laparosc Endosc. 1994;4(6):448-51

24. Liu HP, Chang CH, Lin PJ, Chang JP. Video-assisted endoscopic esophagectomy with stapled intrathoracic esophagogastric anastomosis. World J Surg. 1995; 19(5):745-7.

25. Coosemans W, Lerut TE, Van Raemdonck DE. Thoracoscopic surgery: the Belgian experience. Ann Thorac Surg. 1993;56(3):721-30.

26. Buess G, Becker HD. Minimally invasive surgery in tumors of the esophagus]. Langenbecks Archiv fur Chirurgie Supplement II, Verhandlungen der Deutschen Gesellschaft furChirurgie Deutsche Gesellschaft fur Chirurgie Kongress. 1990. pp. 1355-60.

27. Lloyd DM, Vipond M, Robertson GS, Hanning C, Veitch PS. Thoracoscopic oesophago-gastrectomy-a new technique for intra-thoracic stapling. Endosc Surg Allied Technol. 1994;2(1):26-31.

28. McAnena OJ, Rogers J, Williams NS. Right thoracoscopically assisted oesophagectomy for cancer. Br J Surg. 1994;81(2):236-8.

29. Qu J, Hou W, Gao X. Thoracoscopic esophagectomy for esophageal carcinoma: report of 8 patients. Zhonghua Wai KeZaZhi. 1996;34(2):84-6.

30. Mu J, Gao S, Mao Y, Xue Q, Yuan Z, Li N, et al. Open three-stage transthoracic oesophagectomy versus minimally invasive thoraco-laparoscopic oesophagectomy for oesophageal cancer: protocol for a multicentre prospective, open and parallel, randomised controlled trial. BMJ Open. 2015;5(11):e8328.

31. Kauppila JH, Xie S, Johar A, Markar SR, Lagergren P. Metaanalysis of health-related quality of life after minimally invasive versus open oesophagectomy for oesophageal cancer. BrJSurg. 2017;104(9):1131-40.

32. Charalabopoulos A, Lorenzi B, Kordzadeh A, Tang CB, Kadirkamanathan S, Jayanthi NV. Role of 3D in minimally invasive esophagectomy. Langenbecks Arch Surg. 2017;402(3):555-61.

33. McKeown KC. Total three-stage oesophagectomy for cancer of the oesophagus. BrJSurg. 1976;63(4):259-62.

34. Lewis I. The surgical treatment of carcinoma of the oesophagus; with special reference to a new operation for growths of the middle third. BrJSurg. 1946;34:18-31.

35. U.S. National Library of Medicine. Comparison of Ivor lewis and Tri-incision approaches for patients with esophageal cancer. 2013. https://clinicaltrials.gov/ct2/ show/NCT02017002?term $=$ NCT02017002\&rank $=1$. Accessed 15Dec 2018.

36. Braghetto I, Csendes A, Cardemil G, Burdiles P, Korn O, Valladares H. Open transthoracic or transhiatal esophagectomy versus minimally invasive esophagectomy in terms of morbidity, mortality and survival. Surg Endosc. 2006;20(11):1681-6.

37. Hulscher JB, van Sandick JW, de Boer AG, Wijnhoven BP, Tijssen JG, Fockens P, et al. Extended transthoracic resection compared with limited transhiatal resection for adenocarcinoma of the esophagus. N Engl J Med. 2002;347(21):1662-9.

38. Omloo JM, Lagarde SM, Hulscher JB, Reitsma JB, Fockens $\mathrm{P}$, van Dekken $\mathrm{H}$, et al. Extended transthoracic resection compared with limited transhiatal resection for adenocarcinoma of the mid/distal esophagus: fiveyear survival of a randomized clinical trial. Ann Surg. 2007;246(6):992-1000. discussion-1.

39. Parry K, Ruurda JP, van der Sluis PC, van Hillegersberg R. Current status of laparoscopic transhiatal esophagectomy for esophageal cancer patients: a systematic review of the literature. Dis Esophagus. 2017;30(1):1-7.

40. Puntambekar S, Gauba Y, Chitale M, Manchekar M, Panse M, Halgaonkar P, et al. Evaluation of 5-year results of laparoscopic transhiatal oesophagectomy as a single-centre experience. J Minim Access Surg. 2018; https://doi.org/10. 4103/jmas.jmas_81_18.

41. Aiolfi A, Asti E, Riva CG, Bonavina L. Esophagectomy for stage IV achalasia. Eur J Surg. 2018;50(2):58-64.

42. Briez N, Piessen G, Bonnetain F, Brigand C, Carrere N, Collet D, et al. Open versus laparoscopically-assisted oesophagectomy for cancer: a multicentre randomised controlled phase III trial-the MIRO trial. BMC Cancer. 2011;11:310.

43. Christophe M, Bernard M, Denis P, Cecile D, Denis C, PascalAlexandre T, et al. Hybrid minimally invasive versus open oesophagectomy for patients with oesophageal cancer: A 
multicenter, open-label, randomized phase III controlled trial, the MIRO trial. JClin Oncol. 2015;33(3_suppl):5.

44. MarietteC,MarkarSR, Dabakuyo-YonliTS, Meunier B, Pezet $\mathrm{D}$, ColletD, etal. Hybridminimallyinvasive esophagectomy for esophageal cancer. NEngl J Med. 2019;380(2):152-62.

45. Paireder M, Asari R, Kristo I, Rieder E, Zacherl J, Kabon B, et al. Morbidity in open versus minimally invasive hybrid esophagectomy (MIOMIE). Eur Surg. 2018;50(6):249-55.

46. Kappel-Latif S, Zacherl J, Hejna M, Westerhoff M, Tamandl D, Ba-Ssalamah A, et al. Pancho trial (p53-adapted neoadjuvant chemotherapy for resectable esophageal cancer) completed-mutation rate of the marker higher than expected. EurJ Surg. 2018;50(4):160-6.

47. Berlth F, Plum PS, Chon SH, Gutschow CA, Bollschweiler E, Holscher AH. Total minimally invasive esophagectomy for esophageal adenocarcinoma reduces postoperative pain and pneumonia compared to hybrid esophagectomy. Surg Endosc. 2018; https://doi.org/10.1007/s00464-018-62572.

48. Nilsson M, Kamiya S, Lindblad M, Rouvelas I. Implementation of minimally invasive esophagectomy in a tertiary referral center for esophageal cancer. J Thorac Dis. 2017;9(Suppl 8):S817-S25.

49. Osugi H, Takemura M, Higashino M, Takada N, Lee S, Ueno $\mathrm{M}$, et al. Learning curve of video-assisted thoracoscopic esophagectomy and extensivelymphadenectomy for squamous cell cancer of the thoracic esophagus and results. Surg Endosc. 2003;17(3):515-9.

50. Visser E, van Rossum PSN, van Veer H, Al-Naimi K, Chaudry MA, Cuesta MA, et al. A structured training program for minimally invasive esophagectomy for esophageal cancer-a Delphi consensus study in Europe. Dis Esophagus. 2018; https://doi.org/10.1093/dote/dox124.

51. Verhage RJ, Hazebroek EJ, Boone J, Van Hillegersberg R. Minimally invasive surgery compared to open procedures in esophagectomy for cancer: a systematic review of the literature. Minerva Chir. 2009;64(2):135-46.

52. Nagpal K, Ahmed K, Vats A, Yakoub D, James D, Ashrafian $\mathrm{H}$, et al. Is minimally invasive surgery beneficial in the management of esophageal cancer? A meta-analysis. Surg Endosc. 2010;24(7):1621-9.

53. Guo W, Ma X, Yang S, Zhu X, Qin W, Xiang J, et al. Combined thoracoscopic-laparoscopic esophagectomy versus open esophagectomy: a meta-analysis of outcomes. Surg Endosc. 2016;30(9):3873-81.

54. Luketich JD, Pennathur A, Awais O, Levy RM, Keeley S, Shende M, et al. Outcomes after minimally invasive esophagectomy: review of over 1000 patients. Ann Surg. 2012;256(1):95-103.

55. Biere SS, van Berge Henegouwen MI, Maas KW, Bonavina L, Rosman C, Garcia JR, et al. Minimally invasive versus open oesophagectomy for patients with oesophageal cancer: a multicentre, open-label, randomised controlled trial. Lancet. 2012;379(9829):1887-92.

56. Straatman J, van der Wielen N, Cuesta MA, Daams F, Roig Garcia J, Bonavina L, et al. Minimally invasive versus open esophageal resection: three-year follow-up of the previously reported randomized controlled trial: the TIME trial. AnnSurg. 2017;266(2):232-6.

57. Smithers BM, Gotley DC, Martin I, Thomas JM. Comparison of the outcomes between open and minimally invasive esophagectomy. Ann Surg. 2007;245(2):232-40.

58. Metcalfe C, Avery K, Berrisford R, Barham P, Noble SM, Fernandez AM, et al. Comparing open and minimally invasive surgical procedures for oesophagectomy in the treatment of cancer: the ROMIO (Randomised Oesophagectomy: Minimally Invasive or Open) feasibility study and pilot trial. Health technology assessment. Winch England). 2016;20(48):1-68.

59. Avery KN, Metcalfe C, Berrisford R, Barham CP, Donovan JL, Elliott J, et al. The feasibility of a randomized controlled trial of esophagectomy for esophageal cancer-the ROMIO (Randomized Oesophagectomy: Minimally Invasive or Open) study: protocol for a randomized controlled trial. Trials. 2014;15:200.

60. U.S. National Library of Medicine. Study of Neo-adjuvant Chemotherapy followed by minimal invasive esophagectomy for squamous cell esophageal cancer (NACRFMIE). 2014. https://clinicaltrials.gov/ct2/show/NCT02188615? term $=$ NCT02188615\&rank=1. Accessed 15 Dec 2018.

61. Wang H, Shen Y, Feng M, Zhang Y, Jiang W, Xu S, et al. Outcomes, quality of life, and survival after esophagectomy for squamous cell carcinoma: A propensity score-matched comparison of operative approaches. J Thorac Cardiovasc Surg. 2015;149(4):1006-14. discussion 14-5 e4.

62. Sihag S, Kosinski AS, Gaissert HA, Wright CD, Schipper PH. Minimally Invasive Versus Open Esophagectomy for Esophageal Cancer: A Comparison of Early Surgical Outcomes From The Society of Thoracic Surgeons National Database. Ann Thorac Surg. 2016;101(4):1281-8. discussion 8-9.

63. Mamidanna R, Bottle A, Aylin P, Faiz O, Hanna GB. Shortterm outcomes following open versus minimally invasive esophagectomy for cancer in England: a population-based national study. Ann Surg. 2012;255(2):197-203.

64. Giulianotti PC, Coratti A, Angelini M, Sbrana F, Cecconi S, Balestracci $\mathrm{T}$, et al. Robotics in general surgery: personal experience in a large community hospital. Arch Surg. 2003;138(7):777-84.

65. Bodner J, Wykypiel H, Wetscher G, Schmid T. First experiences with the da Vinci operating robot in thoracic surgery. Eur J Cardiothorac Surg. 2004;25(5):844-51.

66. BodnerJC,ZittM,OttH, Wetscher GJ, WykypielH,Lucciarini P, et al. Robotic-assisted thoracoscopic surgery (RATS) for benign and malignant esophageal tumors. Ann Thorac Surg. 2005;80(4):1202-6.

67. Bodner J, Augustin F, Wykypiel H, Fish J, Muehlmann G, Wetscher G, et al. The da Vinci robotic system for general surgical applications: a critical interim appraisal. Swiss MedWkly. 2005;135(45-46):674-8.

68. Wykypiel H, Wetscher GJ, Klaus A, Schmid T, Gadenstaetter M, Bodner J, et al. Robot-assisted laparoscopic partial posterior fundoplication with the DaVinci system: initial experiences and technical aspects. Langenbecks Arch Surg. 2003;387(11-12):411-6.

69. Augustin F, Bodner J, Wykypiel H, Schwinghammer C, Schmid T. Initial experience with robotic lung lobectomy: report of two different approaches. Surg Endosc. 2011;25(1):108-13.

70. Bodner J, Hoeller E, Wykypiel H, Klingler P, Schmid T. Longterm follow-up after robotic cholecystectomy. Am Surg. 2005;71(4):281-5.

71. Bodner J, Wykypiel H, Greiner A, Kirchmayr W, Freund MC, Margreiter R, et al. Early experience with robotassisted surgery for mediastinal masses. Ann Thorac Surg. 2004;78(1):259-65. discussion 65-6.

72. WykypielHF, BodnerJ, Augustin F, RenzO, HoellerE, Schmid T. Robot-assisted laparoscopic cardiomyotomy. Wien Klin Wochenschr. 2009;121(21-22):707-14.

73. Muhlmann G, Klaus A, Kirchmayr W, Wykypiel H, Unger A, Holler E, et al. DaVinci robotic-assisted laparoscopic bariatric surgery: is it justified in a routine setting? Obes Surg. 2003;13(6):848-54. 
74. Schmid T, Augustin F, Kainz G, Pratschke J, Bodner J. Hybrid video-assisted thoracic surgery-robotic minimally invasive right upper lobe sleeve lobectomy. Ann Thorac Surg. 2011;91(6):1961-5.

75. Biebl M, Andreou A, Chopra S, Denecke C, Pratschke J. Upper gastrointestinal surgery: robotic surgery versus laparoscopic procedures for esophageal malignancy. Visc Med. 2018;34(1):10-5.

76. Horgan S, Berger RA, Elli EF, Espat NJ. Robotic-assisted minimally invasive transhiatal esophagectomy. Am Surg. 2003;69(7):624-6.

77. GuttCN, Bintintan VV, Koninger J, Muller-Stich BP, Reiter M, Buchler MW. Robotic-assisted transhiatal esophagectomy. Langenbecks Arch Surg. 2006;391(4):428-34.

78. Kernstine KH, DeArmond DT, Shamoun DM, Campos JH. The first series of completely robotic esophagectomies with three-field lymphadenectomy: initial experience. Surg Endosc. 2007;21(12):2285-92.

79. Kumar A, Asaf BB. Robotic thoracic surgery: the state of the art. J Minim Access Surg. 2015;11(1):60-7.

80. Sarkaria IS, Rizk NP. Robotic-assisted minimally invasive esophagectomy: the Ivor Lewis approach. ThoracSurg Clin. 2014;24(2):211-22, vii.

81. Okamura A, Watanabe M, Mine S, Nishida K, Imamura Y, Kurogochi T, et al. Factors influencing difficulty of the thoracic procedure in minimally invasive esophagectomy. SurgEndosc. 2016;30(10):4279-85.

82. Kim DJ, Park SY, Lee S, Kim HI, Hyung WJ. Feasibility of a robot-assisted thoracoscopic lymphadenectomy along the recurrent laryngeal nerves in radical esophagectomy for esophageal squamous carcinoma. Surg Endosc. 2014;28(6):1866-73.

83. Dunn DH, Johnson EM, Morphew JA, Dilworth HP, Krueger JL, Banerji N. Robot-assisted transhiatal esophagectomy: a 3-year single-center experience. Dis Esophagus. 2013;26(2):159-66.

84. Boone J, Schipper ME, Moojen WA, Borel Rinkes IH, Cromheecke GJ, van Hillegersberg R. Robot-assisted thoracoscopic oesophagectomy for cancer. Br J Surg. 2009;96(8):878-86.

85. Wykypiel H, Bodner J. Selected commentary to "Robotassisted thoracoscopic oesophagectomy for cancer". Eur Surg. 2009;41(5):241

86. Broussard B, Evans J, Wei B, Cerfolio R. Robotic esophagectomy. JVis Surg. 2016;2:139.

87. Cerfolio RJ, Wei B, Hawn MT, Minnich DJ. Robotic esophagectomy for cancer: early results and lessons learned. Semin Thorac Cardiovasc Surg. 2016;28(1):160-9.

88. Trugeda S, Fernandez-Diaz MJ, Rodriguez-Sanjuan JC, Palazuelos CM, Fernandez-Escalante C, Gomez-Fleitas M. Initial results of robot-assisted Ivor-Lewis oesophagectomy with intrathoracic hand-sewn anastomosis in the prone position. Int J Med Robot. 2014;10(4):397-403.

89. Bongiolatti S, Annecchiarico M, Di Marino M, Boffi B, Borgianni S, Gonfiotti A, et al. Robot-sewn Ivor-Lewis anastomosis: preliminary experience and technical details. Int J Med Robot. 2016;12(3):421-6.

90. Haverkamp L, Seesing MF, Ruurda JP, Boone J, Van Hillegersberg R. Worldwide trends in surgical techniques in the treatment of esophageal and gastroesophagealjunction cancer. Dis Esophagus. 2017;30(1):1-7.

91. van Rossum PS, Haverkamp L, Carvello M, Ruurda JP, van Hillegersberg R. Management and outcome of cervical versus intrathoracic manifestation of cervical anastomotic leakage after transthoracic esophagectomy for cancer. Dis Esophagus. 2017;30(1):1-8.
92. Weksler B, Sharma P, Moudgill N, Chojnacki KA, Rosato EL. Robot-assisted minimally invasive esophagectomy is equivalent to thoracoscopicminimallyinvasive esophagectomy. Dis Esophagus. 2012;25(5):403-9.

93. Yerokun BA, Sun Z, Yang CJ, Gulack BC, Speicher PJ, Adam MA, et al. Minimally invasive versus open esophagectomy for esophageal cancer: a population-based analysis. Ann Thorac Surg. 2016;102(2):416-23.

94. van der Sluis PC, Ruurda JP, Verhage RJ, van der Horst S, Haverkamp L, Siersema PD, et al. Oncologic longterm results of robot-assisted minimally invasive thoracolaparoscopic esophagectomy with two-field lymphadenectomyfor esophageal cancer. AnnSurg Oncol. 2015;22(Suppl 3):S1350-6.

95. Okusanya OT, Sarkaria IS, Hess NR, Nason KS, Sanchez MV, Levy RM, et al. Robotic assisted minimally invasive esophagectomy (RAMIE): the University of Pittsburgh Medical Center initial experience. Ann Cardiothorac Surg. 2017;6(2):179-85.

96. Park SY, Kim DJ, Yu WS, Jung HS. Robot-assisted thoracoscopic esophagectomy with extensive mediastinal lymphadenectomy: experience with 114 consecutive patients with intrathoracic esophageal cancer. Dis Esophagus. 2016;29(4):326-32.

97. van der Sluis PC, van der Horst S, May AM, Schippers C, Brosens LAA, Joore HCA, et al. Robot-assisted minimally invasive thoracolaparoscopic esophagectomy versus open transthoracic esophagectomy for resectable esophageal cancer: a randomized controlled trial. Ann Surg. 2018; https://doi.org/10.1097/sla.0000000000003031.

98. Espinoza-Mercado F, Imai TA, Borgella JD, Sarkissian A, Serna-GallegosD,AlbanRF, etal. Does theapproachmatter? Comparing survivalin robotic, minimallyinvasiveand open esophagectomies. Ann Thorac Surg. 2018;107:378. https:// doi.org/10.1016/j.athoracsur.2018.08.039.

99. Markar SR, Wiggins T, Antonowicz S, Zacharakis E, Hanna GB. Minimally invasive esophagectomy: lateral decubitus vs. prone positioning; systematic review and pooled analysis. Surg Oncol. 2015;24(3):212-9.

100. Seesing MFJ, Goense L, Ruurda JP, Luyer MDP, Nieuwenhuijzen GAP, van Hillegersberg R. Minimally invasive esophagectomy: a propensity score-matched analysis of semiprone versus prone position. Surg Endosc. 2018;32(6):2758-65.

101. Li Z, Li JP, Qin X, Xu BB, Han YD, Liu SD, et al. Threedimensional vs two-dimensional video assisted thoracoscopic esophagectomy for patients with esophageal cancer. World J Gastroenterol. 2015;21(37):10675-82.

102. van der Kaaij RT, van Sandick JW, van der Peet DL, Buma SA, Hartemink KJ. First experience with three-dimensional thoracolaparoscopy in esophageal cancer surgery. J Laparoendosc AdvSurg TechA. 2016;26(10):773-7.

103. Fikfak V, Gaur P, Kim MP. Endoscopic evaluation of gastric conduit perfusion in minimally invasive Ivor Lewis esophagectomy. IntJSurg Case Rep. 2016;19:112-4.

104. Ishiguro T, Kumagai Y, Ono T, Imaizumi H, Honjo H, Suzuki $\mathrm{O}$, et al. Usefulness of indocyanine green angiography for evaluation of blood supply in a reconstructed gastric tube during esophagectomy. IntSurg. 2012;97(4):340-4.

105. Kumagai Y, Hatano S, Sobajima J, Ishiguro T, Fukuchi M, Ishibashi KI, et al. Indocyanine green fluorescence angiography of the reconstructed gastric tube during esophagectomy: efficacy of the 90-second rule. Dis Esophagus. 2018; https://doi.org/10.1093/dote/doy052.

106. Ohi M, Toiyama Y, Mohri Y, Saigusa S, Ichikawa T, Shimura T, et al. Prevalence of anastomotic leak and the impact of indocyanine green fluorescein imaging for evaluating 
blood flow in the gastric conduit following esophageal cancer surgery. Esophagus. 2017;14(4):351-9.

107. Schlottmann F, Patti MG. Evaluation of gastric conduit perfusion during esophagectomy with Indocyanine green fluorescence imaging. J Laparoendosc Adv Surg Tech A. 2017;27(12):1305-8.

108. Shimada Y, Okumura T, Nagata T, Sawada S, Matsui K, Hori R, et al. Usefulness of blood supply visualization by indocyanine green fluorescence for reconstruction during esophagectomy. Esophagus. 2011;8(4):259-66.

109. Dinallo AM, Kolarsick P, Boyan WP, Protyniak B, James A, Dressner RM, et al. Does routine use of indocyanine green fluorescence angiography prevent anastomotic leaks? A retrospective cohort analysis. Am J Surg. 2018; https:// doi. org/10.1016/j.amjsurg.2018.10.027.

110. Pacheco PE, Hill SM, Henriques SM, Paulsen JK, Anderson RC. The novel use of intraoperative laser-induced fluorescence of indocyanine green tissue angiography for evaluation of the gastric conduit in esophageal reconstructive surgery. Am J Surg. 2013;205(3):349-52. discussion 52-3.

111. Hemmerling TM, Schmidt J, Jacobi KE, Klein P. Intraoperative monitoring of the recurrent laryngeal nerve during single-lung ventilation in esophagectomy. Anesth Analg. 2001;92(3):662-4.

112. Garas G, Kayani B, Tolley N, Palazzo F, Athanasiou T, Zacharakis E. Is there a role for intraoperative recurrent laryngeal nerve monitoring during high mediastinal lymph node dissection in three-stage oesophagectomy for oesophageal cancer? Int J Surg. 2013;11(5):370-3.

113. Hikage M, Kamei T, Nakano T, Abe S, Katsura K, Taniyama Y, et al. Impact of routine recurrent laryngeal nerve monitoring in prone esophagectomy with mediastinal lymph node dissection. SurgEndosc. 2017;31(7):2986-96.

114. Ikeda Y, Inoue T, Ogawa E, Horikawa M, Inaba T, Fukushima R. Recurrent laryngeal nerve monitoring during thoracoscopic esophagectomy. World J Surg. 2014;38(4):897-901.

115. Kobayashi H, Kondo M, Mizumoto M, Hashida H, Kaihara S, Hosotani R. Technique and surgical outcomes of mesenterization and intra-operative neural monitoring to reduce recurrent laryngeal nerve paralysis after thoracoscopic esophagectomy: A cohort study. Int J Surg. 2018;56:301-6.

116. SchmidtJ, IrouschekA, Heinrich S, Oster O, Klein P, Birkholz T. Recurrent laryngeal nerve monitoring during esophagectomy and mediastinal lymph node dissection: a novel approach using a single-lumen endotracheal EMG tube and the EZ-blocker. World J Surg. 2012;36(12):2946-7. author reply 8.

117. Tsang RK, Law S. Adaptation of continuous intraoperative vagus nerve stimulation for monitoring of recurrent laryngeal nerve during minimally invasive esophagectomy. World J Surg. 2016;40(1):137-41.

118. Wong I, Tong DKH, Tsang RKY, Wong CLY, Chan DKK, Chan FSY, et al. Continuous intraoperative vagus nerve stimulation for monitoring of recurrent laryngeal nerve during minimally invasive esophagectomy. J Vis Surg. 2017;3:9.

119. Yuda M, Nishikawa K, Takahashi K, Kurogochi T, Tanaka Y, Matsumoto A, et al. A strategy for using Intraoperative nerve monitoring during esophagectomy to prevent recurrent laryngeal nerve palsy. Anticancer Res. 2018;38(3):1563-7.

120. Zhong D, Zhou Y, Li Y, Wang Y, Zhou W, Cheng Q, et al. Intraoperative recurrent laryngeal nerve monitoring: a useful method for patients with esophageal cancer. Dis Esophagus. 2014;27(5):444-51.
121. Findlay JM, Tustian E, Millo J, Klucniks A, Sgromo B, Marshall RE, et al. The effect of formalizing enhanced recovery after esophagectomy with a protocol. Dis Esophagus. 2015;28(6):567-73.

122. Giacopuzzi S, Weindelmayer J, Treppiedi E, Bencivenga M, Ceola M, Priolo S, et al. Enhanced recovery after surgery protocol in patients undergoing esophagectomy for cancer: a single center experience. Dis Esophagus. 2017;30(4):1-6.

123. Lemmens L, van Zelm R, Borel Rinkes I, van Hillegersberg R, Kerkkamp H. Clinical and organizational content of clinical pathways for digestive surgery: a systematic review. Dig Surg. 2009;26(2):91-9.

124. Oh TK, Jeon JH, Lee JM, Kim MS, Kim JH, Lim H, et al. Association of high-dose postoperative opioids with recurrence riskin esophageal squamous cell carcinoma: reinterpreting ERAS protocols for long-term oncologic surgery outcomes. Dis Esophagus. 2017;30(10):1-8.

125. Pisarska M, Malczak P, Major P, Wysocki M, Budzynski A, Pedziwiatr M. Enhanced recovery after surgery protocol in oesophageal cancer surgery: Systematic review and metaanalysis. PLoS ONE. 2017;12(3):e174382.

126. Yost MT, JolissaintJS, Fields AC, Fisichella PM. Enhanced recovery pathways for minimallyinvasive esophageal surgery. JLaparoendosc Adv Surg Tech A. 2018;28(5):496-500.

127. Cao S, Zhao G, Cui J, Dong Q, Qi S, Xin Y, et al. Fasttrack rehabilitation program and conventional care after esophagectomy: a retrospective controlled cohort study. Support Care Cancer. 2013;21(3):707-14.

128. Cerfolio RJ, Bryant AS, Bass CS, Alexander JR, Bartolucci AA. Fast tracking after Ivor Lewis esophagogastrectomy. Chest. 2004;126(4):1187-94.

129. Chen L, Sun L, Lang Y, Wu J, Yao L, Ning J, et al. Fasttrack surgery improves postoperative clinical recovery and cellular and humoral immunity after esophagectomy for esophageal cancer. BMC Cancer. 2016;16:449.

130. Gemmill EH, Humes DJ, Catton JA. Systematic review of enhanced recovery after gastro-oesophageal cancer surgery. Ann R Coll Surg Engl. 2015;97(3):173-9.

131. Jiang K, Cheng L, Wang JJ, Li JS, Nie J. Fast track clinical pathway implications in esophagogastrectomy. World J Gastroenterol. 2009;15(4):496-501.

132. Shewale JB, Correa AM, Baker CM, Villafane-Ferriol N, HofstetterWL, JordanVS, etal. Impact ofafast-trackesophagectomy protocol on esophageal cancer patient outcomes and hospital charges. Ann Surg. 2015;261(6):1114-23.

133. Weijs TJ, Kumagai K, Berkelmans GH, Nieuwenhuijzen GA, Nilsson M,LuyerMD. Nasogastric decompressionfollowing esophagectomy: a systematic literature review and metaanalysis. Dis Esophagus. 2017;30(3):1-8.

134. Dünser MW, Kwizera A. Perioperative fluid management. Eur Surg. 2017;49(1):41-8.

135. Adamova Z, Slováček R. Effects of preoperative carbohydrate drinks on postoperative outcome after colorectal surgery. Eur Surg. 2017;49(4):180-6.

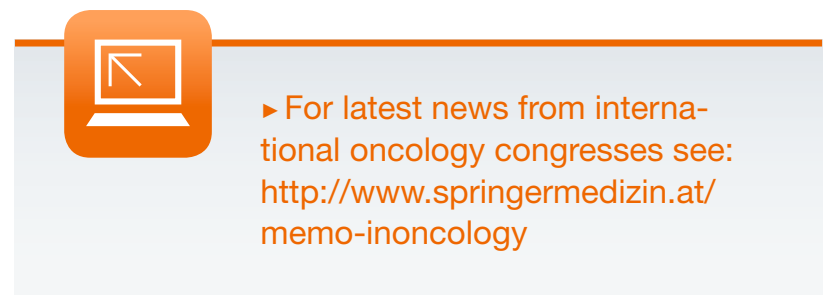

